\title{
Crenças de Mães e Professoras sobre o DESENVOLVIMENTO DA CRIANÇA
}

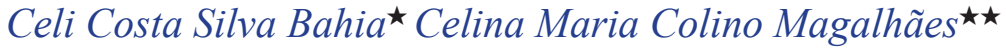 \\ Fernando Augusto Ramos Pontes ${ }^{\star \star}$
}

\begin{abstract}
Resumo
Estudos têm revelado uma ligação entre a maneira como os adultos pensam e as formas como eles se relacionam com as crianças. Este estudo objetivou levantar as crenças de mães e professoras sobre o desenvolvimento da criança que freqüenta o ambiente de creche e identificar se as crenças se dirigem para as características de competências ou de disfunções. Participaram deste estudo 28 adultos (16 mães e 12 professoras). Para coletar os dados utilizou-se o grupo focal e para interpretá-los a análise de conteúdo. Os resultados apontaram que as participantes possuem a mesma crença (ambientalista) sobre desenvolvimento, mas têm concepções diferentes quanto à direção em que o contexto familiar el ou da creche influencia no desenvolvimento. A análise indica que a formação inicial e continuada das profissionais precisa contemplar aspectos específicos do desenvolvimento infantil para que crenças mais adequadas sejam construídas $e$ compartilhadas com as familias de crianças que frequentam ambientes coletivos.
\end{abstract}

Palavras-chave: crença; creche; mães; professoras.

\section{Mothers AND TEACHERS' BELIEFS ABOUT THE DEVELOPMENT OF THE CHILD}

\begin{abstract}
Studies have shown a link between the way the adults think and the forms they become related with the children. This study had as objective to know the mothers and teachers' beliefs about the development of the child who frequents

$\star$ Pedagoga. Doutora em Teoria e Pesquisa do Comportamento pela Universidade Federal do Pará. Professora do Instituto de Ciências da Educação - Faculdade de Educação - UFPA, Pesquisadora do Grupo de Estudos e Pesquisa em Educação Infantil - IPÊ-UFPA.

E-mail: celibahia@yahoo.com.br

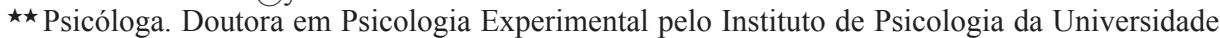
de São Paulo. Professora do Departamento de Psicologia Experimental do Centro de Filosofia e Ciências Humanas da Universidade Federal do Pará. Orientadora no Programa de PósGraduação em Teoria e Pesquisa do Comportamento-UFPA.

E-mail: celina.magalhaes@pesquisador.cnpq.br

$\star \star \star$ Psicólogo. Doutor em Psicologia Experimental pelo Instituto de Psicologia da Universidade de São Paulo. Professor do Departamento de Psicologia Experimental do Centro de Filosofia e Ciências Humanas da Universidade Federal do Pará. Orientador no Programa de Pós-Graduação em Teoria e Pesquisa do Comportamento-UFPA

E-mail: fernando.pontes@pesquisador.cnpq.br
\end{abstract}


the day-care center to identify if the beliefs had characteristics of abilities or dysfunctions. Twenty-eight adults had participated in this study (16 mothers and 12 teachers). To collect the data it was utilized the focal group and to interpret them, the analysis of the content. The results had pointed that the participants have the same belief (environmentalist) about the development, but have different conceptions about the direction where the familiar context and/or of the day-care center influences in the development. The analysis indicates that the initial and continued formation of the professionals needs to contemplate specific aspects of the children development so the more adjusted beliefs can be constructed and shared with the families of children who frequent collective environments.

Keywords: belief; day-care center; mother; teachers.

Como nos últimos anos os pesquisadores do desenvolvimento vêm indicando a estreita relação entre o comportamento do indivíduo e o seu contexto imediato e distante e sendo as crenças um componente do contexto, a literatura vem evidenciando o estudo destas como um aspecto importante para se compreender o desenvolvimento humano. De acordo com Miller (1988), uma das razões para se investigar as crenças dos educadores é porque o pensamento que eles possuem sobre as crianças influencia a maneira como se relacionam com elas e, consequentemente, o desenvolvimento infantil.

Goodnow (1988) argumenta que o número de pesquisas que relacionam as crenças dos pais com as ações destes ainda é limitado e destaca o risco de resultados ambíguos por se tratar de resposta dos pais sobre suas ações, ou seja, ela considera que alguns estudos que estabelecem essa relação investigam crenças sobre práticas como se estivessem investigando as práticas. Esta autora apresenta outros motivos para se estudar as crenças dos educadores, como: a) as ideias dos pais são uma interessante forma de cognição e desenvolvimento; b) as ideias dos pais fornecem ajuda à compreensão da ação destes; c) as ideias dos pais são um aspecto da ideia do contexto no qual a criança se desenvolve, e d) o estudo das ideias em duas gerações pode fornecer alguns insights para a compreensão da transmissão e da mudança cultural.

Apesar da restrição de Goodnow $(1988,1996)$, alguns estudos (RUBIANO; ROSSETI-FERREIRA, 1985; RUBIANO, 1990; ROSSETTI-FERREIRA; AMORIM; VITÓRIA, 1994; CAMPOS DE CARVALHO; RUBIANO, 1994, 1996; LEVINE; MILLER; RICHMAN, 1996; BUCHANAN et al., 1998; McMULLEN, 1999; LORDELO; FONSECA; ARAÚJO, 2000) vêm apontando para a influência das ideias dos adultos sobre as relações que são estabelecidas entre estes e as crianças, em ambientes coletivos ou familiares. Assim, esses autores compartilham do ponto de vista de Miller (1988) ao argumentar que os adultos têm noções ou ideias a respeito de como tratar as crianças, isto é, suas práticas na relação com elas estão sustentadas no que acreditam ser bom ou ruim, naquilo que eles valorizam ou desvalorizam. 
Buscando conhecer a relação entre crença e prática, Lordelo, Fonseca e Araújo (2000) investigaram o ambiente doméstico, em termos de responsividade materna às demandas da criança, relacionada a atitudes frente à maternidade e à criança. Fizeram parte do estudo 45 díades de uma favela urbana e de bairros de classe média que foram filmadas e entrevistadas em suas casas sobre questões relativas à maternidade e ao cuidado à criança. Também foi aplicado um questionário investigando atitudes em relação à maternidade e à autonomia da criança. Os resultados apontaram que, em relação à autonomia da criança, houve diferenças significativas, relacionadas ao bairro de residência e ao nível de escolaridade. Indicaram ainda que as mães tendem a se comportar diferentemente, segundo suas condições de vida. Elas parecem pensar a maternidade e a educação de suas crianças conforme os contextos em que vivem.

Nesta direção LeVine, Miller e Richman (1996) investigaram a relação entre escolaridade, crenças, práticas de cuidado e educação de filhos e como estas influenciam a comunicação que estabelecem com eles. Fizeram parte do estudo 75 díades mãe-bebê mexicanas, pertencentes a dois níveis socioeconômicos distintos e com diferentes níveis de escolaridade. Os dados foram coletados por meio de observações realizadas nas residências de mães em interação com seus bebês na faixa etária de cinco a 15 meses. Os principais resultados revelaram que os modelos de habilidade comunicativa dos bebês variam de acordo com o grupo cultural. Para a maioria das mães, os bebês são considerados incapazes de se comunicar e não se engajam em diálogos. Também foi evidenciada uma estreita relação entre a escolarização e as crenças maternas no que se refere às habilidades comunicativas do bebê. Essas crenças influenciam no engajamento das mães em interações verbais com seus filhos e, consequentemente, no desenvolvimento dos bebês.

Nestes estudos é possível perceber que as crenças influenciam na maneira como as mães se relacionam com seus filhos e parecem intimamente associadas com a escolaridade que estas possuem. Assim, a literatura vem sugerindo que as crenças e práticas maternas são resultantes de um equilíbrio entre o modo como as mães foram educadas, suas experiências de vida, os valores culturais vigentes em seu ambiente próximo e distante, e as circunstâncias das suas vidas presentes, em termos de características materiais e simbólicas dos ambientes em que vivem.

Ainda que os estudos revelem que as crenças maternas influenciam na maneira como as mães se comportam com os seus filhos, considera-se relevante levantar os estudos que investigam a relação entre crença e prática em ambientes coletivos, pois estes apresentam características distintas do ambiente familiar. A seguir, apresentamos alguns trabalhos investigando crenças de professoras.

Frang (1996), McMullen (1999), Vartuli (1999) argumentam que as expectativas dos professores sobre o comportamento das crianças e sobre as decisões a serem tomadas são guiadas por princípios filosóficos e/ou pelo sistema de crenças. O posicionamento das autoras nos faz perceber que o viés apontado por elas para as ações das professoras está baseado nas crenças que estas possuem. Este posicionamento foi investigado por Rubiano e Rosseti-Ferreira (1985), Rubiano (1990), Campos de Carvalho e Rubiano (1994, 1996) e Rossetti-Ferreira, 
Amorim e Vitória (1994), as quais constataram que as ideias das professoras sobre a criança norteiam seus comportamentos junto a esta, pois influenciam na maneira como a educadora organiza o ambiente e, consequentemente, no modo como se relaciona com as crianças, o que, em última instância, vai influenciar no desenvolvimento dos pequenos.

Como a psicologia dos cuidadores é um aspecto importante para se compreender o processo de constituição da criança, Hyson e Lee (1996) realizaram uma pesquisa com o objetivo de desenvolver uma medida para as crenças de professoras de educação infantil sobre emoção. Foi utilizado um instrumento com 40 itens para medir as crenças emocionais de 279 professoras americanas. Como resultado, as autoras encontraram que as crenças emocionais estavam relacionadas com o nível de conhecimento das professoras acerca de aspectos específicos do trabalho voltado à educação da criança.

McMullen (1999) buscou compreender a discrepância entre as crenças sobre desenvolvimento e a prática em sala de aula. Esse estudo foi realizado com 20 professoras com formação e experiência profissional diferenciada que trabalhavam com crianças de até oito anos de idade. Foram aplicados questionários e, em seguida, os pesquisadores observavam os comportamentos das educadoras em sala de aula durante duas visitas de $01 \mathrm{~h} 30 \mathrm{~min}$ de duração. Os resultados apontam que há menor discrepância entre crenças e práticas de professoras com curso acadêmico em educação infantil e as que têm experiência com crianças em préescolas do que entre professoras que têm somente título de educação elementar e sem experiência com pré-escola.

Buchanan et al. (1998), estudando a influência da formação e da experiência nas crenças dos professores, identificaram que os professores formados recentemente tinham crenças e práticas mais apropriadas ao desenvolvimento das crianças do que os professores com mais experiência. Apesar de argumentarem que as crenças dos professores começam a ser formadas bem antes de entrarem nos cursos de formação de professores, os autores ressaltam a influência da formação no sistema de crenças adotadas pelos professores.

Os dados acima nos permitem compreender que discutir as crenças das professoras é de fundamental importância na construção da qualidade de ambientes coletivos para as crianças, especialmente nesse momento em que a identidade da creche (cuidar/educar) ainda se encontra em processo de construção (OLIVEIRA, 1999). Muitas educadoras de creche, herdeiras de uma concepção assistencialista, ainda estão marcadas pela ideia de que as necessidades da criança se restringem à alimentação, à higienização e à formação de hábitos. Outras, com uma perspectiva de creche com função educativa, têm dificuldade em aceitar que os cuidados são intrínsecos ao educar.

A análise dos trabalhos acima citados nos permite perceber que as crenças são formadas a partir das experiências vividas, tanto no contexto pessoal quanto no profissional, e a formação, ainda que seja extremamente importante na construção das crenças, não as determina. Para Oliveira (2001), no processo de formação de educadoras, em vez de se partir da visão elaborada previamente, 
o fundamental seria iniciar pela visão que as professoras têm sobre a criança e sobre a educação desta. Desse modo, é essencial conhecer as crenças das educadoras para se trabalhar na melhoria dos cursos de formação.

Mesmo sabendo-se que na contemporaneidade a criança passa grande parte do seu tempo no contexto familiar e na creche, no levantamento realizado foi encontrado apenas o estudo de Edwards, Gandini e Giovaninni (1996) investigando crenças de pais e professores pré-escolares. Esse trabalho tinha por objetivo determinar a distância nas crenças sobre desenvolvimento infantil entre pais e professores pré-escolares. Fizeram parte do estudo 240 adultos (pais, mães e professores) pertencentes a duas comunidades, uma nos Estados Unidos e outra na Itália. Foi utilizado para coleta de dados um questionário com 38 itens, subdividido em sete categorias. Os principais achados indicaram que os pais são mais influenciados pelo modelo cultural de desenvolvimento infantil de suas comunidades do que os professores, pois estes compartilham internacionalmente outros fundamentos de educação paralelos ou equivalentes a outras culturas e têm uma vasta experiência com crianças. Os pesquisadores concluíram que o treinamento e a responsabilidade emergem como o elemento mais forte das expectativas de desenvolvimento do que a cultura, ou seja, eles evidenciaram a relação entre as crenças dos adultos e o nível de escolaridade.

Para além dos trabalhos que investigam a relação entre crença e prática, no levantamento realizado também encontraram-se trabalhos (PALÁCIOS, 1990; MELCHIORI; BIASOLI, 2001; SEIDL DE MOURA et al., 2004) que investigam a constituição das crenças, ou seja, quais os fatores que influenciam na construção destas. Esses trabalhos, de maneira geral, apontam que as ideias dos cuidadores são resultantes da influência de diferentes fatores, como a escolarização, as experiências de vida, os valores culturais vigentes em seu ambiente próximo e distante, e as circunstâncias das suas vidas presentes, em termos de características materiais e simbólicas dos ambientes em que vivem.

Na contemporaneidade, a educação e o cuidado das crianças são compartilhados pelo ambiente familiar e pela creche. Se considerarmos que a psicologia dos educadores influencia na maneira como eles se relacionam com as crianças, em ambiente doméstico ou coletivo, e, consequentemente, no desenvolvimento delas, o estudo das crenças de mães e professoras de creche é relevante para se conhecer as oportunidades desenvolvimentais que estão sendo oferecidas às crianças nesses dois ambientes. Porém o levantamento da literatura revelou que há poucas pesquisas que procuram contrastar crenças de mães e de professoras.

Esta argumentação fundamenta-se no pressuposto de que, para Bronfenbrenner e Morris (1998), um dos aspectos necessários ao desenvolvimento é a continuidade dos Processos Proximais, entendidos como as formas particulares de interação entre os indivíduos em diferentes contextos, as quais produzem dois tipos de efeito, as características de competência e as características de disfunção. A primeira referese à aquisição de conhecimentos, habilidades e capacidades para produzir e dirigir o comportamento. Já a segunda refere-se às manifestações recorrentes de dificuldade em manter o controle e a integração de comportamentos. Assim, as características de 
competências servem para manter a relação, e as disfunções dificultam-na. Então, nesta linha de raciocínio, para se levantar a continuidade e/ou descontinuidade dos processos proximais, um bom caminho é o conhecimento das crenças dos sujeitos que participam do processo educativo da criança.

Tendo por base as argumentações acima, o presente estudo objetivou conhecer as crenças de mães e professoras sobre o desenvolvimento da criança que frequenta o ambiente de creche, identificar se as crenças dirigem-se para as características de competências ou de disfunções. Objetivou ainda analisar os fatores que interferem no desenvolvimento das dimensões e nas características de competência ou de disfunção.

\section{MÉTodo}

\section{Participantes}

Fizeram parte deste estudo 28 adultos, sendo 16 mães e 12 professoras que trabalhavam com crianças na faixa etária de zero a três anos que frequentavam ambientes de creche. No tocante à escolarização, $45 \%$ das mães da amostra apresentavam o Ensino Fundamental completo ou incompleto, e 55\%, o Ensino Médio completo ou incompleto. Em se tratando da atividade profissional, 42,85\% encontravam-se desempregadas; das que trabalhavam, $28,57 \%$ faziam parte do mercado formal, atuando como garçonete, zeladora e recepcionista, e $28,57 \%$ trabalhavam no mercado informal como diarista, lavadeira, vendedora de alimentos e manicure.

As professoras são exclusivamente do sexo feminino e estão na faixa etária de 30 a 50 anos. Destas, $90 \%$ são mães, sendo que apenas uma tem filho com menos de três anos. No que se refere à formação, $50 \%$ das participantes possuem nível médio, com habilitação em magistério, e estão fazendo ou pretendem fazer curso superior. As demais possuem curso superior em áreas diversas (licenciatura em pedagogia, em história, em geografia, etc.). Quanto à experiência profissional, $60 \%$ das participantes trabalham na educação infantil há mais de vinte anos, e as demais têm ,no mínimo, nove anos de experiência. A maioria (65\%) das professoras iniciou a vida profissional trabalhando em projetos de assistência à criança (Casulo e/ou creche-FUNPAPA), as demais em pré-escola particular, sendo que já atuaram ou estão atuando no Ensino Fundamental. Isso significa que todas tiveram algum tipo de experiência profissional anterior ao trabalho na creche.

\section{$O$ contexto da pesquisa}

O estudo foi realizado em uma Unidade de Educação Infantil da Secretaria Municipal de Educação, situada em um bairro de periferia da cidade de Belém. A Unidade atende 205 crianças na faixa etária entre seis e sessenta meses de idade pertencentes a uma população de baixo nível socioeconômico. 


\section{Instrumentos}

Tendo em vista o alcance dos objetivos, foi elaborado um roteiro cujo eixo principal era a criança que frequenta o ambiente de creche. $\mathrm{O}$ roteiro foi desdobrado em várias questões, tais como: quem são as crianças, como elas são, por que elas apresentam determinados comportamentos, como elas aprendem e se desenvolvem, o que elas precisam para crescerem e aprenderem. Além destes, algumas surgiram durante o debate, portanto não haviam sido previstas.

\section{Procedimento}

Após aprovação do projeto em 19/1/2004 pelo Comitê de Ética em pesquisa envolvendo seres humanos do NMT/UFPA, protocolo número 008/2004, foi feito contato com a Coordenação de Educação Infantil (COEDI), da Secretaria Municipal de Educação e, em seguida, com a Coordenadora da creche, para explicitar os objetivos do trabalho, bem como solicitar autorização para a sua realização. Nesse momento, foi solicitada a contribuição da coordenadora da creche de forma a possibilitar o contato com as educadoras (mães e professoras) das crianças atendidas na instituição.

Para a realização do grupo focal, primeiramente selecionaram-se as mães, considerando o seguinte critério: ser mãe de crianças que estivessem frequentando regularmente a creche. A partir desse critério, as mães foram divididas em dois grupos: as com participação ativa e as com participação eventual. Foram consideradas mães com participação ativa aquelas que vão regularmente à creche no horário de entrada e saída, que buscam informações sobre seu filho e sobre o espaço e informam questões relevantes sobre sua criança. Foram consideradas mães com participação eventual aquelas que só vão à creche quando são insistentemente chamadas pelos profissionais da instituição.

As mães foram contatadas individualmente e convidadas a participar de alguns encontros com duração de uma hora e meia a duas horas, em dias e horários a serem combinados. A maioria apresentou dificuldade em função da falta de tempo. Diante da dificuldade apresentada pelas mães, decidiu-se realizar um único encontro com duração de três horas e meia a quatro horas, no dia e horário a ser combinados. Após a confirmação do local, dia e horário para a realização do encontro, com o objetivo de ratificá-lo, foram entregues 12 informativos, para garantir a participação de no mínimo oito mães, pois imprevistos poderiam ocorrer e alguma não ter condições de comparecer.

Com relação à realização do grupo focal com as professoras, a coordenadora informou que seria muito difícil envolvê-las, pois elas não teriam possibilidade de estar na creche em outro horário, uma vez que, em geral, elas têm outras atividades. A maioria tem outro emprego, é estudante ou tem seus compromissos familiares. A coordenadora informou que a única possibilidade seria realizar o encontro no horário de trabalho, pois elas deixariam as crianças sob a responsabilidade das estagiárias, contudo isso não poderia ocorrer muitas vezes, pois 
as crianças demandam muita atenção e as estagiárias poderiam ter dificuldades. Diante dos limites encontrados, foram realizados dois encontros com as professoras, nos seus respectivos horários de trabalho.

\section{Realização do grupo focal}

No dia marcado para a realização dos encontros, o espaço, que havia sido disponibilizado pela coordenadora, foi organizado de acordo com as orientações propostas pela metodologia do grupo focal. Uma mesa retangular foi disposta no centro da sala. Em direção a cada cadeira foi fixada uma etiqueta com o nome das participantes que foram contatadas, do moderador e dos observadores. Essa organização, além de possibilitar a identificação e a interação face a face dos participantes no grupo, tinha por objetivo evitar a ideia de prestígio de alguém e possibilitar a comunicação não verbal, permitindo assim que tanto o moderador quanto os observadores registrassem, além das falas, as expressões dos participantes.

Considerando que o tempo previsto para a realização do grupo focal era em média de três horas e meia a quatro horas, foi organizado um lanche com doces, salgados e refrigerantes, para se evitar possíveis desconfortos e tornar o momento o mais descontraído possível.

Inicialmente, o moderador apresentava-se, agradecia a participação de todos, esclarecia os objetivos e os procedimentos. Neste momento, explicava a necessidade de gravar o diálogo, enfatizando que as informações seriam utilizadas exclusivamente para a pesquisa. Em seguida, discutia o Termo de Consentimento Livre e Esclarecido, ressaltando o sigilo das respostas. Após a concordância em participar, as mães e as professoras assinaram esse Termo, o qual ficou guardado com a pesquisadora.

Após a assinatura do Termo, o moderador ressaltava que a participação de todos era muito importante, e solicitava que os demais participantes também se apresentassem. Ao final de cada apresentação, o moderador agradecia à pessoa. Depois que todos se apresentaram, o moderador lançou a primeira questão para o debate, solicitando que as mães falassem de suas crianças. Ele encorajava todos a participar e buscava esclarecer as ideias do grupo perguntando: o que, como, para que, por que, e até solicitava algum exemplo que pudesse esclarecer o ponto de vista das participantes. Esse procedimento foi adotado para a exploração de todas as questões presentes no roteiro.

O tempo de duração dos encontros variou entre três e quatro horas, pois as mães menos participativas tiveram participação limitada, talvez pelo fato de terem poucas informações sobre as questões que estavam em discussão.

Com relação à realização do grupo focal com as professoras, de maneira geral os encaminhamentos foram semelhantes aos realizados com as mães. Contudo, a participação das professoras foi diferenciada, principalmente porque algumas afirmavam que as colegas já haviam falado tudo o que tinham para dizer. 
Ao final de cada encontro, o moderador solicitava a apreciação do grupo sobre o evento. A maioria das participantes o considerou muito interessante e sugeriu que outros deveriam acontecer com maior regularidade na creche. As professoras mencionaram ainda que o encontro possibilitou uma autorreflexão acerca das suas práticas.

\section{ANÁLiSE dos DADOS}

O material coletado no grupo focal foi analisado tendo por inspiração as orientações teórico-metodológicas propostas pela análise de conteúdo de Bardin (1994). Assim, após a transcrição das gravações realizadas durante o grupo focal, iniciou-se a análise do conteúdo das entrevistadas.

Primeiramente foi processado o recorte de conteúdos. Os relatos foram decompostos e, em seguida, recompostos constituindo os eixos, por exemplo: as dimensões do desenvolvimento, a direção em que estas se apresentam e os fatores que o influenciam. O recorte de conteúdo possibilitou visualizar, compreender e expressar melhor os significados do discurso dos participantes. Os fragmentos dos discursos (recortes de conteúdo), manifestos em palavras, expressões ou ideias, compuseram os eixos de análise. Na organização destes, utilizou-se o modelo aberto, pois eles não foram fixados no início, mas durante o curso da análise.

Posteriormente, considerando os objetivos da pesquisa, foi processada a reorganização dos eixos, de tal maneira que uma análise mais detalhada dos recortes fosse possível.

\section{Resultados e Discussão}

\section{As crenças de mães e professoras}

Entendendo crença como ideia e que é possível inferi-la a partir do que as pessoas falam, organizaram-se as crenças das participantes tendo por base as dimensões do desenvolvimento, quais sejam: a dimensão "afetivo-emocional", envolvendo verbalizações referentes à proteção, à atenção, ao contato afetuoso; a dimensão "cognitiva", envolvendo verbalizações referentes ao comportamento de observação, de atenção, de compreensão, de imitação, de curiosidade; a dimensão "social", envolvendo verbalizações que indicam comportamento de interação da criança com os pares e com os adultos, bem como o domínio da linguagem oral pela criança; e a dimensão "físico-motora", envolvendo verbalizações referentes aos comportamentos de pular, subir/descer, brincar. Em cada dimensão, analisouse se as crenças dirigem-se para o que Bronfenbrenner (1999) chama de características de competências ou características de disfunções. Ou seja, analisou-se se as crenças das participantes estão pautadas em conhecimentos, habilidades e capacidades para produzir e dirigir o comportamento ou em manifestações de dificuldade em manter o controle e a integração de comportamentos. Também se analisaram os fatores que interferem no desenvolvimento das dimensões e nas características de competência ou de disfunção. 
A leitura de competências ou disfunção é relevante para se pensar as ações das educadoras (mães e professoras), pois essas expectativas podem servir como direção geral para o comportamento destas. De acordo com Goodnow (1988), adultos que esperam o desenvolvimento em uma área podem direcionar suas ações para esta, premiando ou punindo o comportamento das crianças, sugerindo assim que, para essa autora, as expectativas são causa e efeito do comportamento das crianças.

No tocante às dimensões do desenvolvimento, as professoras destacam a afetivo-emocional.

[...] são crianças carentes tanto da questão afetiva quanto da questão financeira (p. GO).

[...] Elas são carentes de carinho, de afeto, de atenção, de tudo $[\ldots]$ (P. LE).

[...] São crianças que necessitam muito de afeto, de carinho, né, esse amor que a gente vê (p. NE).

[...] A carência de carinho torna as crianças agressivas [...] tem um que é muito agressivo. Ele já me bateu, já me chutou" (p. SA).

[...] quando elas [crianças] chegam, elas chegam com um determinado, digamos assim, comportamento, elas chegam assim, mais inseguras. Chegam assim, muito carentes de afeto, [...] essas crianças são carentes, elas precisam de apoio, elas precisam de afeto, elas precisam de carinho, elas precisam de um abraço, né e precisam de um beijo, precisam de um cheiro (p. GO).

[...] são crianças carentes, são crianças que necessitam dos nossos cuidados e da nossa proteção (p. GS).

O conteúdo das verbalizações acima indica que em se tratando da dimensão afetivo-emocional as professoras se referem às características de disfunção, pois consideram que as crianças são carentes, ou seja, falta-lhes carinho, afeto, atenção etc. Essa carência ocasiona insegurança e agressividade, isto é, as dificuldades comportamentais são causadas por falta de contato afetuoso. Assim, para as professoras, a carência de carinho é a razão de as crianças necessitarem da atenção e do carinho que são oferecidos na creche.

As verbalizações das professoras relativas à dimensão afetivo-emocional foram acompanhadas de comentários, explicações e/ou justificativas, as quais apontam para a influência do contexto familiar na carência da criança. Os motivos apresentados para essa influência são diversos: indisponibilidade dos pais (ex: "a gente vive em uma sociedade mesmo que o pai tem que trabalhar mesmo 
pra sustentar, tem que ter a comida mesmo. Às vezes não tem tempo, tem 2, 4, 3 filhos, às vezes fica difícil”" (p. GS); falta de atenção dos pais (ex: "[...] essas crianças não têm carinho, só são tratadas com gritos, com pancada. Aí quando chega uma pessoa assim eles se agarram com unhas e dentes nas pessoas, porque querem carinho" (p. GO); "a criança, ela passa despercebida muitas vezes pelo pai, pela mãe e muitas vezes pelo avô" (p. SA), "[...] os pais não se preocupam com a saúde, [...] eu não tô generalizando, mas muitas delas é um descaso total, não há aquela preocupação de levar o filho ao médico, de não... quer se ver livre da criança, eu vejo desse lado...(p.LE) e a baixa escolaridade dos pais (ex: "educação dos pais como um todo ela é muito precária"(p. GO).

Tendo por base os comentários, explicações e/ou justificativas apresentadas pelas participantes do microssistema profissional, percebe-se que a ideia de disfunção afetivo-emocional parece estar associada às condições socioeconômicas e culturais das famílias. Assim, suas ideias estão pautadas no que Bronfenbrenner (1999) chama de endereço social, ou seja, o desenvolvimento da criança é explicado a partir do contexto onde elas vivem. Apesar de concordamos com Bandioli e Mantovani (1998), no sentido de que é uma abstração pensar na criança separada da realidade social na qual se encontra inserida e, portanto, separada das necessidades da própria família, é importante considerar que outros contextos, como a creche, também influenciam no comportamento da criança e não apenas o seu endereço social.

Além da dimensão afetivo-emocional, encontra-se a presença da dimensão social, como uma característica de competência no comportamento das crianças.

[...] eles interagem muito bem entre eles, eles interagem muito bem. [...] os mais velhos eles vão, eles cuidam, eles ficam "Olha vai aqui bebê", eles pegam na mão, [...] às vezes os pequenos não querem, eles ficam, puxam a mão, e os mais velhos querem alguma coisa, querem estar cuidando. $\mathrm{E}$ os mais novos ficam puxando a mão, eles querem liberdade, eles querem brincar (p.SO).

[...] tem criança que fala com o olhar, tem uma situação que eu tava com um bebê no colo, o A estava no colo e ele comunica com o olhar, é uma criança que ainda num fala, não verbaliza, mas pelo olhar se comunica [...] (p. GI).

[...] Eles começam "aaah...", o que foi? O que tu vistes aí? O que aconteceu? Aí eles começam a apontar, "o que foi? O que aconteceu, fala?", aí eles apontam e murmuram mordeu, bateu, caiu ou caaarrr, que caaarrrr?. Ou eles ficam na porta da lavanderia batendo na porta, "O que você quer aí?" "caaarrro", que são aqueles velocípedes que ficam guardados lá dentro. Vão procurando uma forma, um jeito de dizer o que é que foi (p.GS). 
Pode-se observar que as verbalizações acima revelam as competências da criança para a interação, pois interagem e expressam seus desejos e necessidades de diversas maneiras, ou seja, mesmo que não domine a linguagem oral, a criança utiliza outras formas de comunicação com os adultos e/ou com os seus pares. De acordo com as verbalizações, parece que tanto os coetâneos quanto os adultos são responsivos às competências das crianças, pois as interpretam e buscam atendê-las.

A dimensão cognitiva também é ressaltada, sendo considerada uma característica de competência presente nas crenças das professoras.

[...] as crianças questionam, elas são questionadoras, um exemplo: "ei tia por que ainda não saiu o almoço ein?", eu digo, olha porque as crianças estão demorando a comer ou então saiu tarde mesmo, por- que eles custaram a descongelar a comida mas logo eles vão chamar. Daí ele diz "ah eu vou já lá", eu deixo ele ir, "aah eu vou lá, pode?", "pode, eu vou lá abro a porta e levo lá na coordenação", aí muitas vezes eles acham graça e voltam. Mas sempre tem um ou dois que vão lá e dizem "eu vou lá mesmo perguntar”, vá, vá lá perguntar (p.SA).

[...] eles são questionadores, eles falam, eles questionam, [...] aqui eles questionam e isso desde bebê quando eles não tão a fim de ficar sentados pra almoçar eles não ficam, não; a primeira palavra é não (p.SO).

A dimensão cognitiva é evidenciada nos comportamentos de imitação, de observação, de compreensão e de questionamento manifestos pelas crianças desde pequenas.

Como característica de competência também foi encontrada a dimensão físico-motora nas crenças das professoras.

[...] me encanta perceber que coisas que a minha filha com 6 anos de idade demorou muito pra ter uma autonomia, ela ainda faz tolice na mesa e eles não, às vezes, com dois anos, eles já têm atitudes assim, meu Deus, se com 2 anos já estão assim quando tiverem com [...] (p.GI).

[...] quase enfartei porque a $\mathrm{E}$, a primeira vez que ela desceu no escorrega ela subiu só e desceu só, quase que eu infarto. Porque pra mim uma menina de menos de dois anos já estar subindo só no escorrega é demais fazer isso (GS).

$\mathrm{Na}$ creche, as crianças amadurecem muito rápido, amadurecem muito rápido (p.SA). 
A dimensão físico-motora, vista como característica de competência, é evidenciada nos comportamentos apresentados pelas crianças que frequentam ambiente de creche, os quais, de modo geral, são manifestados por crianças com mais idade.

As verbalizações das professoras referentes às dimensões cognitiva, social e físico-motora também foram acompanhadas de comentários, explicações e/ou justificativas que evidenciam a influência do contexto da creche nas características de competência para os comportamentos correspondentes a estas dimensões. Os motivos apresentados para esta influência são:

[...] o espaço (ex: "elas encontraram aqui um espaço pra se desenvolver $[\ldots]$ a gente está criando crianças autônomas", [...] (p. GI); o trabalho desenvolvido, ex. "[...] esse trabalho que a gente está desenvolvendo é importante. As crianças quando elas chegam, elas chegam, elas são mais inseguras. Passado o tempo a gente percebe que elas se desenvolvem. Elas começam a interagir umas com as outras. A questão da partilha, porque o individualismo é uma questão muito presente, porque, passado o tempo, elas começam a agir, elas começam a se desenvolver, elas começam a compartilhar umas com as outras!” (p. GO); “[...] eles vão crescendo e a gente vê "olha essa aqui é uma obra-prima minha. Fui eu quem fiz ele ficar assim". Uma criança de berçário com dois, três anos tu vais fazer a cabeça dela" ( $p$. SA); a atenção recebida (ex. "como eles observam muito, e a gente tá sempre ali dando uma atenção, e eles um pouco que refletem também esse cuidado, né. Geralmente com o mais novo, com aquele que tá chorando, aquele que tá mais carente naquele momento, e isso tende a aumentar. Quando eles vão ficando mais velhos eles têm um cuidado maior, eles refletem no..." (p. SO), "eles são realmente assim muito curiosos, eu vejo assim [...] no dia-a-dia, as nossas atitudes, assim, refletem muito neles" (p. GS).

De acordo com os comentários e/ou justificativas das profissionais, é possível perceber que para elas a creche exerce um papel importante no desenvolvimento de competência nas dimensões cognitivas, sociais e fisico-motoras da criança.

Ao contrário da dimensão afetivo-emocional, marcada por características de disfunção, uma vez que as verbalizações são direcionadas para a ausência de características que favoreçam os comportamentos da criança nesta dimensão, as dimensões cognitiva, social e físico-motora são direcionadas para as características de competências, pois evidenciam conhecimentos, habilidades e capacidades das crianças para produzirem e dirigirem seus comportamentos. 
No tocante às crenças das mães sobre o desenvolvimento da criança, observa-se a presença das dimensões afetivo-emocional, cognitiva, social e físico-motora. Para essas dimensões as mães destacam apenas as características de competência manifestadas pelas crianças.

$\mathrm{Na}$ dimensão afetivo-emocional, algumas mães assim se manifestam "ela é muito carinhosa com os coleguinhas, ela é muito boazinha [...]" (m. RO); "elas são muito amáveis, umas crianças hiper, muito boa" (m. RS).

As manifestações acima revelam o reconhecimento da competência afetivoemocional das crianças, a qual é expressa pelas palavras carinhosa, amável e boa.

Além da dimensão afetivo-emocional, foi possível perceber a presença da dimensão social no desenvolvimento infantil.

Ela é muito "comunicativa", tudo que acontece aqui ela conta em casa, se alguém maltrata, se alguém fala alguma coisa que, né [...] ela faz muita pergunta mesmo, sobre aqui também na creche, né. Também o que acontece em casa. Ela chega me conta as coisas, faz um monte de pergunta (m. EL).

[...] tudo ela fala direitinho, não tem erro de português, né, assim de falar, de se expressar, não. Ela diz "oi, mamãe", "bom-dia, mamãe", "boa noite, papai" (m. JO).

As verbalizações referentes à dimensão social estão voltadas para as competências comunicativas da criança, seja porque ela fala sobre o que lhe ocorre na creche, fato este que parece ser utilizado como uma das estratégias para a mãe obter informações acerca do que ocorre no cotidiano da instituição, seja pelo fato de verbalizar as palavras corretamente.

A dimensão cognitiva do desenvolvimento também está presente e pode ser visualizada nas verbalizações abaixo.

Ela é muito curiosa e muito inteligente. [...] Ela sabe o nome de todos os amigos, ela vai fazer três anos, sabe o nome de todos os amigos, das professoras novas, todo mundo ela sabe o nome, dos que não são da sala dela, tudo o que acontece ela fala direitinho $[\ldots]$ (m.GI).

Ah ele é muito inteligente, credo! o pequenininho, meu Jesus é muito! Ele conversa muito, ele gosta muito de perguntar as coisas, ele conversa, conversa, conversa [...] (m. MA).

[...] ela é esperta, presta atenção, ela não pergunta, mas ela vê o que as outras crianças fazem, o que as outras pessoas fazem e ela quer fazer, e até mesmo pela televisão o pouco que ela assiste ela copia (m. CA). 
[...] ele é muito curioso [...] ele é curioso em tudo, em tudo. Ele tem muita curiosidade, até quando a gente tá conversando ele tá no meio, qualquer coisa ele tá perguntando (m. AN).

[...] elas são muito curiosas, são muito falantes, tudo elas perguntam. Elas tão naquela fase dos porquês" (m. RS).

[...] as crianças que estão na creche elas são mais curiosas, elas conversam mais, elas perguntam mais [...] (m. EL).

Pode-se observar, no conteúdo das verbalizações acima, que as mães destacam as competências nos comportamentos de observação, atenção e curiosidade manifestadas pelas crianças.

Quanto à dimensão físico-motora, as mães também se manifestam focalizando as competências das crianças, como se pode observar nas verbalizações abaixo.

[...] crianças, são muito travessas. Eles são muito levados. Eles pulam $[\ldots]$ (m. MA).

Ele é assim, ele é peralta, uma criança, ele não para [...] ele mexe, ele sobe, e não pode ver um som, ele é muito ativo (m. AN).

[...] meu bebê é muito sapeca, eu acho que ele é sim porque toda vez que eu chego eu vejo a professora correndo atrás dele e ele tá subindo nas coisas, [...] tem que ter muita paciência com ele, muita mesma" (m. MA).

É uma bênção o meu filho, ele só falta derrubar a casa, é uma bênção mesmo, sobe tudo (m. FA).

Nas manifestações das mães, nota-se uma relação entre a competência fisicomotora e o comportamento de brincar, pular, correr e manusear coisas. Desse modo, uma síntese preliminar das verbalizações das mães nos permite perceber que, para elas, as crianças são competentes em todas as dimensões do desenvolvimento.

As verbalizações das mães acerca das diversas dimensões do desenvolvimento também foram acompanhadas de comentários, explicações e/ou justificativas que evidenciam a influência do contexto familiar e da creche nas competências das crianças nas diferentes dimensões.

As mães apresentam vários motivos para justificar a influência do contexto familiar nas competências apresentadas pelas crianças, nas dimensões do desenvolvimento mencionadas acima, dentre estas,

[...] o carinho recebido (ex. "[...] Elas têm uma convivência boa, nós somos pobres, mas claro, pobre não é defeito, pobreza não é defeito, né. Então elas tentam mostrar que 
elas são bem amadas, né [...]” (m. RS); "eu crio o meu filho com muito amor, muito mesmo, mas quando ele precisa, eu dou uma palmadinha na bunda dele porque não pode deixar sem limites. Eu dou muito amor pro meu bebê" (m. FA); "[...] somos muito afetivos com os nossos filhos, [...] são uns filhos muito queridos. Eu acho que quando a gente contribui com a afetividade, com um carinho com os nossos filhos eles retribuem pra gente também com carinho e com amor [...] quando a gente dá-lhe uma palmada, às vezes, não por ignorância, mas repreendendo, disciplinando eles..." (m. JO). Atenção recebida (ex. "eu procuro buscar um tempinho, deixar um pouco os meus compromissos e ficar um pouco com elas, [...] ter um carinho especial de mãe, de professora é especial, mas nem tanto quanto da mãe" (m. RS); "eu ajudo ele, ensino o que ele tem que fazer [...] eu acredito que eu tô contribuindo, eu acredito que se não fosse eu e o pai dele ele não ia ser [...] e a professora também, eu acho que ela ajuda bastante" (m. AN). Diálogo (ex."Porque eu acho que não adianta viver o tempo todo batendo na criança, [...] eu acho que a pancada não dá jeito, não conserta, mas o que conserta é as palavras, é o diálogo com os nossos filhos" (m. CA); "em casa é assim 'olha J. não é assim, não, não faça isso' Olha é muito feio tomar do prato dos outros, é muito feio morder os outros, é muito feio você comer exagerado" (m. JO). Imitação (ex. "tudo que ela vê ela conta, as histórias que a avó dela conta, ela pega as bonecas e conta. Quando chega em casa ela fica contando história pra tudo que é boneca" (m.GI); "ele chama uns palavrãozinhos (rs). Ele aprende lá em casa mesmo com as meninas que ficam falando, a vizinha lá do lado, [...] aí criança tudo fala, tudo repete, é igual papagaio" (m. EL).

Nas verbalizações das mães sobre as dimensões do desenvolvimento e da influência do contexto familiar no processo de constituição da criança, é possível perceber a importância atribuída ao carinho, à atenção e ao afeto no comportamento de suas crianças. Observa-se também que as mães se percebem como agentes socializadores de suas crianças. Assim, revelam disponibilizar parte do seu tempo para interagir com os filhos, por meio do diálogo e de brincadeiras. E colaboram com o trabalho educativo da creche, ensinando e aconselhando os filhos sobre o que acreditam ser certo e/ou errado.

Em se tratando da contribuição da creche para o desenvolvimento das competências, nas dimensões do desenvolvimento mencionadas acima, as mães apresentam motivos diversos:

[...] dentre eles as relações estabelecidas, ex. "[...] o envolvimento dela tá sendo proveitoso, porque ela tá envolvida com as crianças, com as brincadeiras" (m. EI); 
"porque na creche eles conversam, vejam vídeo, eles fazem desenho, tem as reuniões né, tem as brincadeiras didáticas, educativas, disso, daquilo né" (m.VA); "na creche a criança tá convivendo com outras crianças, [...], elas ficam conversando, aí até perde a vergonha" (m. VI). O trabalho desenvolvido, ex. "na creche elas [as professoras] não admitem quem fala "ada", [...] porque se disser "ada", não é ada é "água", e você abre bem esse água que é pra criança falar direito (m. JO); "ela aprendeu muito, tipo assim, eu nunca parei pra ensinar pra ela, as cores, hoje ela já sabe. Os números ela tá aprendendo, com três anos ela sabe contar, então, quer dizer que com a professora ela aprendeu muito, desenvolveu muito" (m. CA); [...] elas recebem uma educação que eu não posso dar em casa, é diferente, por exemplo, aprender a desenhar, se envolver. Aquele tempo que as professora têm disponível pra ensinar eu não tenho lá (m. RO); "Tem pessoas que amam mesmo os nossos filhos de verdade, eu tenho certeza, que cuidam muito bem. Então é muito importante esse afeto que elas têm pelos nossos filhos" (m. RS). A estimulação recebida, ex. "foi aqui que ela aprendeu a comer sozinha, foi aqui que ela aprendeu a pegar nas coisas, no caneco. Aprendeu a se alimentar sozinha" (m. EL); "Aqui as crianças aprendem a comer sozinhas né, [...] aqui elas têm um jeito, cada uma das professoras tem um jeitinho de dar uma comida. Até iniciar a criança a pegar e dominar, equilibrar o copo e a colher. Aí vai começando aquele processo de educação" (m. VI); "quando ele chegou aqui ele não sabia nem pegar na comida ainda, no pratinho, sentar pra comer, aí ele já começou a pegar no copo pra beber água que ele não sabia, e depois com um tempo ele foi sabendo" (m. VA).

Em síntese, segundo as mães, seus filhos aprendem muitas coisas na creche, seja por meio dos estímulos (audiovisual, desenhos, brincadeiras) oferecidos, seja por meio da interação com os pares e/ou da imitação do comportamento de outras crianças, seja ainda por meio das relações, principalmente afetivas, com a professora.

Olhando para as verbalizações das dimensões do desenvolvimento (afetivo-emocionais, cognitivas, sociais e físico-motoras), apresentadas pelas participantes dos dois microssistemas, percebe-se que elas reconhecem a criança como um ser com potencialidades para interagir com o outro (adulto ou criança) e que seu desenvolvimento ocorre por meio dessas interações. Desse modo, parece que as crianças são vistas como participantes ativas do seu desenvolvimento, ou seja, os comportamentos e habilidades que manifestam são derivados das suas experiências no contexto da família e da creche.

Um olhar imediato para a influência das relações no processo de desenvolvimento da criança nos faz pensar que a visão unidirecional e passiva de criança vem sendo aos poucos substituída por uma concepção de que a criança se constitui na interação com o seu contexto físico-social. Contudo, quando 
se observam os comentários, as explicações e/ou as justificativas apresentados para os comportamentos manifestados pelas crianças, parece que o foco ainda é basicamente na influência que o ambiente exerce, ou seja, ela é uma consequência daquilo que vem de fora dela, como se fosse produto do ambiente. Assim, pouco se percebe a ideia de que a criança, com suas características individuais, também influencia no ambiente.

Dada essa constatação, é possível inferir que as crenças das professoras e mães sobre desenvolvimento infantil são ambientalistas, pois se referem basicamente à influência do contexto familiar e/ou da creche na maneira como a criança se comporta. Como exemplo desta crença, uma professora assim se manifesta: "o meio influencia muito na formação da personalidade. Eu acho que todos nós somos produtos do meio. (...) o meio é determinante na formação, no caráter do indivíduo" (p. GO). Sendo assim, parece que a criança é resultado das condições ambientais em que vive.

Resgatando o estudo realizado por Palácios (1990), o qual aponta três classes de pais: modernos (acreditam que as diferenças individuais resultam da interação entre os fatores hereditários e ambientais), tradicionais (revelam ideias inatistas) e paradoxais (são ambientalistas), pode-se considerar que tanto as professoras quanto as mães participantes desta pesquisa são paradoxais, pois são ambientalistas, ou seja, consideram que o que a criança é pode ser atribuído à força que o ambiente exerce no seu desenvolvimento.

Apesar de os dois grupos considerarem o contexto para explicar o comportamento das crianças, a direção em que estes influenciam é diferenciada, particularmente no que se refere à dimensão afetivo-emocional. Para as professoras, a dimensão afetivo-emocional está associada às características de disfunção e é atribuída ao ambiente familiar, principalmente em função das condições socioeconômicas e culturais das famílias. Já as dimensões cognitivas, sociais e físico-motoras estão associadas às características de competência e são atribuídas ao ambiente da creche, sugerindo uma influência positiva da creche/professoras sobre essas dimensões do desenvolvimento. Sendo assim, parece que, para as professoras, as famílias contribuem negativamente para o desenvolvimento da criança, enquanto a creche contribui positivamente.

As justificativas das professoras no que se refere à contribuição negativa da família nos fazem perceber que as explicações para os comportamentos das crianças ainda estão focalizadas no seu endereço social, ou seja, parece que as condições socioeconômicas e culturais das famílias são os únicos aspectos considerados quando se trata do desenvolvimento afetivo-emocional das crianças que frequentam ambiente de creche. Desse modo, as outras experiências dos pequenos, em outros contextos, inclusive a creche, têm pouca importância na constituição de disfunções e/ou competências nessa dimensão.

Considerando que as crenças na dimensão afetivo-emocional são distintas entre as participantes dos dois microssistemas, então, se as crenças influenciam nas ações dos adultos, é provável que a maneira como estes estão se relacionando com as crianças, nos dois contextos, seja distinta. Logo, se as mães estão acre- 
ditando na competência afetivo-emocional das suas crianças é provável que elas estejam buscando relações que promovam contatos afetuosos com seus filhos. Ao contrário, como as professoras consideram que as crianças não apresentam competência afetiva, é possível que elas não promovam interações proximais que favoreçam relações afetuosas entre as crianças e delas com os adultos.

Essa percepção parece que se diferencia no que se refere às competências cognitivas, sociais e físico-motoras, pois aparece apenas o contexto da creche contribuindo na constituição dessas competências. Desse modo, as experiências da criança, em outros contextos, inclusive familiar, têm pouca influência na constituição das suas competências. Assim, parece que cada contexto influencia de modo distinto e independente no desenvolvimento da criança, bem como não se percebe, nas verbalizações das participantes, indicadores do quanto a criança influencia nesses ambientes.

Algumas possíveis explicações para as verbalizações das professoras quanto à direção em que o contexto familiar e a creche/professora influenciam no desenvolvimento da criança são visualizadas. Uma vez que suas crenças estão centradas no endereço social, parece que as famílias ainda são vistas como incapazes de contribuir positivamente com o desenvolvimento dos seus filhos; as professoras manifestam-se a partir daquilo que acreditam ser a função da escola/ creche, qual seja, a transmissão de valores e comportamentos adequados à vida em sociedade; ao afirmarem que influenciam no comportamento da criança, as professoras estão falando sobre elas próprias e sentem-se pouco à vontade em revelar as possíveis fragilidades do trabalho que realizam, por esse motivo destacam apenas a contribuição positiva deste.

Para as mães, todas as dimensões estão associadas às características de competência e são atribuídas ao contexto familiar e da creche. As justificativas para a influência do contexto familiar estão situadas, principalmente, na atenção e no carinho que a criança recebe, sugerindo assim que as experiências no contexto familiar operam positivamente para o desenvolvimento da criança. Já as justificativas para a influência da creche estão voltadas para as relações estabelecidas com a professora e com as crianças, mas também para o trabalho desenvolvido pela instituição. Talvez a ênfase das mães nas características de competência das crianças deva-se ao fato de que elas estejam falando dos seus filhos, com quem estabelecem vínculos afetivos, e não das crianças de maneira geral.

A compreensão das mães acerca do reconhecimento da competência das crianças associada às experiências na família, como também na creche, é relevante, pois indica que elas estão se percebendo como sujeitos que participam do processo educativo da criança. Essa percepção muito tem a contribuir para a superação da ideia de que a família delega para a creche a responsabilidade da educação dos seus filhos.

Como se pode perceber, há divergência de opinião entre as participantes dos dois subsistemas quanto à direção em que o ambiente familiar influencia no desenvolvimento da criança. Divergências de opiniões quanto à direção em que os diferentes contextos influenciam no desenvolvimento da criança também 
foram evidenciadas por Melchior e Biasoli-Alves (2001). Neste estudo, para as professoras, a sua influência é sempre positiva, enquanto as mães influenciam positiva e negativamente no desenvolvimento da criança.

Apesar de os resultados serem semelhantes nestes dois estudos, argumentamos em favor da realização de outras pesquisas investigando a direção em que os contextos influenciam no desenvolvimento da criança para se evitar opiniões consideradas preconceituosas sobre as famílias. Essa necessidade se amplia principalmente pelo fato de que as mães se consideram participantes ativas do processo educativo dos seus filhos. Ressalta-se que o ponto de vista das mães participantes deste estudo também foi identificado por Moreira (1999), evidenciando que elas reconhecem as características positivas das suas crianças, bem como se consideram protagonistas da criação e da educação dos seus filhos.

A necessidade de ampliação das pesquisas sobre a direção em que diferentes contextos influenciam no desenvolvimento da criança é reforçada com base nos argumentos apresentados por Géis (1994), a qual considera uma inverdade que os pais das camadas populares apresentam descaso e desinteresse pela educação dos filhos. Esta autora ainda acrescenta que, mesmo sendo idealizadas as representações de educação que os pais possuem, eles demonstram estar interessados e empenhados no desenvolvimento de suas crianças. O ponto de vista desta autora é fortalecido quando se analisam aqui as manifestações das mães sobre seus filhos.

Apesar da divergência em relação à direção em que os diferentes contextos influenciam no desenvolvimento da criança, constatou-se coerência quanto à crença sobre desenvolvimento. As participantes dos dois microssistemas acreditam que o ambiente influencia na constituição da criança. Como interpretar essa coerência em grupos distintos, principalmente no que diz respeito à escolarização, uma vez que a literatura vem indicando a influência que esta exerce na formação das crenças?

Sem pretender negar a importância da escolarização na formação das crenças, destacamos a experiência das profissionais e das mães como um elemento que pode influenciar na formação das crenças das participantes, mesmo porque, como afirma Goodnow (1988), a construção das crenças se dá a partir da incorporação da visão dos outros, por meio de conhecimentos recebidos, mas também por meio da experiência, pois elas são autoconstruídas. Assim, é possível que as crenças das professoras sejam influenciadas pelo processo de se tornar profissional, mas também por intermédio das suas experiências com diversas crianças, inclusive com seus filhos. Já as crenças das mães parecem refletir os conhecimentos sobre as crianças, que são compartilhados por meio das trocas com os filhos, mas também por meio de diversas fontes, tais como revistas, televisão, grupos de vizinhos e outras instituições, entre elas, a creche. Como afirma Goodnow (1988), as experiências podem não estar localizadas apenas nas experiências diretas dos pais com os filhos, mas em experiências externas à família.

Essa compreensão nos remete ao estudo de Seidl de Moura et al. (2004), o qual sugere que a política de atendimento materno-infantil da cidade de Porto Alegre pode estar propiciando conhecimentos específicos às mães sobre o seu 
bebê, independentemente da escolaridade que elas possuem, confirmando assim que as crenças são influenciadas por múltiplos contextos (GOODNOW, 1988), mesmo porque, como afirma Bronfenbrenner (1996), o indivíduo se desenvolve por meio das relações que estabelece em diferentes contextos.

A partir das reflexões acima, a semelhança entre as crenças dos dois microssistemas faz-nos pensar que na creche há uma interinfluência entre as crenças de mães e de professoras. Essa interinfluência é relevante para a promoção da relação creche-família, enquanto espaço de construção e reconstrução de crenças, de professoras e de mães, e, possivelmente, de mudanças nas oportunidades educativas oferecidas à criança, tanto na creche como na família.

Além das reflexões em torno da experiência das participantes, e considerando a influência da escolarização na formação das crenças, necessário se faz ler esse dado com base na formação das profissionais, pois, ainda que $50 \%$ das participantes tenham formação em nível superior, os cursos que realizaram são em diferentes áreas e nem sempre contemplam discussões referentes ao desenvolvimento infantil. Desse modo, com base nos dados deste estudo, bem como nos resultados encontrados por McMullen (1999) e Hyson e Lee (1996), argumentase que a formação inicial e continuada das profissionais que trabalham com crianças precisa contemplar aspectos específicos do desenvolvimento infantil para que crenças mais adequadas sejam construídas e compartilhadas com as famílias de crianças que frequentam ambientes coletivos.

\section{Considerações Finais}

O estudo das crenças de mães e professores revelou-se importante para conhecermos um dos componentes do macrossistema, o qual representa uma das faces do processo de constituição da criança que frequenta o ambiente de creche. Essa importância é evidenciada principalmente se considerarmos a existência de divergência entre crenças das participantes dos dois microssistemas, no que se refere à direção em que o contexto da creche e o da família influenciam nas características de competência e de disfunção da criança. Por que essa divergência é importante? Porque, se considerarmos que as crenças influenciam nas interações, então existe uma descontinuidade dos processos proximais em que a criança está envolvida.

Apesar de a literatura indicar a existência de relação entre crença e prática, Goodnow (1988) argumenta que poucos estudos foram realizados investigando a influência das crenças sobre a prática. Segundo este autor, o estudo das crenças não é suficiente para se inferir as relações que se estabelecem, mas é importante para se compreender o processo de desenvolvimento da criança que frequenta o ambiente de creche. Para compreender tal processo, é necessário combinar o levantamento das crenças com dados observacionais das relações estabelecidas entre adulto-criança neste espaço, pois outros fatores, além das crenças, podem influenciar nas relações que ali se estabelecem. Essa constatação sugere a necessidade da Inserção Ecológica no espaço da creche para se buscar a relação entre as crenças e o comportamento dos participantes. 
A metodologia do grupo focal mostrou-se pertinente para a coleta de informações sobre crenças de mães e professoras. Contudo, é necessária a realização de outras pesquisas, utilizando-se outros instrumentos para aprofundar a direção em que os contextos influenciam no desenvolvimento da criança, pois neste estudo tivemos dificuldade de contar com a participação dos sujeitos, particularmente as professoras, em três ou mais encontros, o que representou uma limitação na coleta de informações. Se tivéssemos realizado mais encontros, teríamos mais informações que nos permitiriam fazer outras análises das interações estabelecidas no microssistema e das semelhanças e diferenças entre as crenças das mães e professoras de creche.

\section{REFERÊNCIAS}

BANDIOLI A.; MANTOVANI, S. Manual de Educação Infantil: 0 a 03 anos. Tradução de R. S. Di Leone e Alba Olmi. Porto Alegre: ArtMed, 1998.

BARDIN, L. Análise de conteúdo. Lisboa: Edições 69, 1994.

BRONFENBRENNER, U. A ecologia do desenvolvimento humano: experiências naturais e planejadas. Tradução de M. A. Verosese. Porto Alegre: Artes Médicas, 1996.

BRONFENBRENNER, U.; MORRIS, P. The ecology of developmental processes. In: DAMON, W. (Org.). Handbook of child psychology. New York: 1998. p. 9931027.

BRONFENBRENNER, U. Environments in developmental perspective: theoretical and operational models. In: FRIEDMANN, B. L.; WACHS, T. D. (Org.). Conceptualization and assessment of environment across the life span. Washington, DC: American Psychologial Association, 1999. p. 3-30.

BUCHANAN, T. et al. Predictors of the developmental appropriateness of the beliefs and practices of first, second and third grade teachers. Early Childood Research Quarterly, [S.1.], v. 13, n. 3, 459-483, 1998.

CAMPOS DE CARVALHO, M. I.; RUBIANO, M. R. B. Organização do espaço em instituições. In: OLIVEIRA, Z. M. R. de (Org.). Educação Infantil: muitos olhares. São Paulo: Cortez, 1994. p. 107-137.

CAMPOS-DE-CARVALHO, M. I.; RUBIANO, M. R. B. Rede social de crianças pequenas em creche: análise por proximidade física e atividade compartilhada. Psicologia: Teoria e Pesquisa, Brasília, v. 12, n. 2, p. 129-136, 1996. 
EDWARDS, C. P., GANDINI, L.; GIOVANINNI, D. The constrasting developmental timetables of parents and preschool teachers in two cultural communities. In: HARKNESS, S.; SUPER, C. M. (Org.). Parents' cultural belief systems. New York: Guiford, 1996. p 270-288.

FRANG, Z. A review of research on teacher beliefs and practices. Educational Research, v. 38, n. 1, p. 47-65, 1996.

GEIS, R. M. Criar ou educar crianças? Estudo das representações de mães e de educadoras sobre o papel da creche. 1994. Tese (Doutorado)-Instituto de Psicologia: Universidade de São Paulo. São Paulo, 1994.

GOODNOW, J. J. Parents'ideas, actions, and feelings: models and methods from developmental and social psychology. Child Development, [S.1.], v. 59, n. 2, p. 286-320, Apr. 1988.

GOODNOW, J. J. From household practices to parents' ideas about work. In: HARKNESS, S.; SUPER, C. M. (Org.). Parents' cultural belief systems. New York: Guiford, 1996. p. 270-288.

HYSON, M. C.; LEE, K. M. Assessing early childhood teachers' beliefs about emotions: content, contexts and implications for practice. Early Education and Development, [S.1.], v. 7, n. 1, p. 68-78, 1996.

LEVINE, A. R.; MILLER, P. M.; RICHMAN, A. L. Education and mother- infant interaction: a mexican case study. In: HARKNESS, S.; SUPER, C. M. (Org.). Parents' cultural belief systems. New York: Guiford, 1996. p. 254-269.

LORDELO, E.; FONSECA, A.; ARAUJO, M. L. V. B. Responsividade do ambiente de desenvolvimento: crenças e práticas como sistema cultural de criação de filhos. Psicologia: Reflexão Crítica, v. 13, n. 1, p. 73-80, 2000.

McMULLEN, M. B. Characteristcs of teachers who talk the DAP talk and walk the DAP walk. Journal of Research in childhood Education, [S.1.], v. 13, n. 2, p. 216-230, 1999.

MELCHIORI, L.; BIASOLI-ALVES, Z. M. M. Crenças de Educadoras de Creche sobre temperamento e desenvolvimento de bebês. Psicologia: Teoria e Pesquisa, v. 17, n. 3, p. 285-292, 2001.

MILLER, S. A. Parent's beliefs about children's cognitive development. Child Development, [S.1.], v. 59, n. 2, p. 259-285, Apr. 1988. 
MOREIRA, L. Concepção de mães usuárias de creche sobre educação de filhos. 1999. Dissertação (Mestrado)-Universidade Federal da Bahia, Bahia, 1999.

OLIVEIRA, S. M. L. Crenças e valores de educadoras de creche sobre o desenvolvimento e educação de crianças de 2 e 3 anos. 1999. Dissertação (Mestrado)-Universidade de Brasília, Brasília, 1999.

OLIVEIRA, S. M. L. Crenças e valores dos profissionais de creche e a importância da formação continuada na construção de um novo papel junto à criança de 0 a 3 anos. Aberto, v. 18, n. 73, p. 89-97, 2001.

PALÁCIOS, J. Parents' ideas about the development and education of their children: answers to some questions. International Journal of Behavioral Development, v. 13, n. 2, p. 137-155, 1990.

ROSSETTI-FERREIRA, M. C.; AMORIM, K. S.; VITÓRIA, T. A Creche enquanto contexto possível de desenvolvimento da criança pequena. Revista Brasileira de Crescimento e Desenvolvimento Humano, São Paulo, v. 4, n. 2, p. 35-40, 1994.

RUBIANO, M. E. B.; ROSSETTI-FERREIRA, M. C. Avaliação longitudinal do desenvolvimento psicológico em crianças de creche. In: REUNIÃO ANUAL DE PSICOLOGIA, 15., 1985, Ribeirão Preto. Resumos... Ribeirão Preto: Sociedade de Psicologia de Ribeirão Preto, 1985, p. 119.

RUBIANO, M. E. B. Suportes ambientais e organização social de crianças em creche. 1990. Tese (Doutorado)-Universidade de São Paulo, São Paulo, 1990.

SEIDL DE MOURA. L. M., et al. Conhecimento sobre desenvolvimento infantil em mães primíparas de diferentes centros urbanos do Brasil. Estudo de Psicologia, v. 9, n. 3, 2004.

VARTULI, S. How early childhood teacher beliefs vary across grade level. Early Childhood Research Quarterly, [S.1.], v. 14, n. 4, p. 489-514, 1999.

Recebido em: setembro de 2009

Aceito em: janeiro de 2011 